\title{
SPECTRUM OF BENIGN AND MALIGNANT HEMATOLOGICAL DISEASES DIAGNOSED IN QUETTA ON BONE MARROW ASPIRATION.
}

1. MBBS, M.Phil (Haematology) Demonstrator Pathology Bolan University of Medical \& Health Sciences Quetta.

2. MBBS, M.Phil (Haematology) Demonstrator Pathology Services Institute of Medical Sciences, Lahore.

3. MBBS, M.Phil (Haematology) Senior Demonstrator Pathology Gujranwala Medical College, Gujranwala.

4. MBBS, FCPS (Medicine) Senior Registrar (Medical Unit-II) Bolan Medical Complex Hospital, Quetta.

Correspondence Address:

Dr. Ayesha Samad Dogar

Demonstrator Pathology

Bolan University of Medical \& Health

Sciences Quetta.

drayeshasamaddogar@yahoo.com

Article received on:

02/10/2019

Accepted for publication: $30 / 12 / 2019$

\section{Ayesha Samad Dogar ${ }^{1}$, Beenish Ejaz ${ }^{2}$, Hafiz Ather Farooq ${ }^{3}$, Tariq Mahmood ${ }^{4}$}

ABSTRACT... Objectives: Bone marrow aspiration is a diagnostic test for various hematological disorders. Present study was designed to determine the percentages and frequency of benign and malignant hematological disorders diagnosed on bone marrow aspiration in Quetta. Study Design: Cross sectional study. Setting: Department of Hematology Sandeman Provincial Teaching Hospital Quetta and Bolan Medical Complex Quetta. Period: From Jan 2015 to Jan 2019. Material \& Methods: The demographic variables were age and gender of the patients, while the research variables were benign hematological disorders and malignant hematological disorders. All the variables were presented in percentages and frequencies. Results: Out of total 478 hematological disorders $241(50.4 \%)$ were diagnosed with benign and $237(49.6 \%)$ were malignant hematological disorders. Majority of the patients were in the age range between 1-10 years. $62.3 \%$ was the male population whereas females comprised of only $37.7 \%$. Megaloblastic Anemia having $14.2 \%$ was found to be the most common benign hematological disorders followed by Aplastic Anemia with $11.7 \%$ cases and Idiopathic Thrombocytopenic Purpura was present in $9.2 \%$. Among the malignant disorders Acute Lymphocytic Leukemia 19\%, Chronic Myeloid Leukemia $8.3 \%$ and Acute Myeloid Leukemia were found to be $5.8 \%$. Conclusion: The most common benign hematological disorders were Megaloblastic anemia and Aplastic anemia whereas Acute Lymphocytic Leukemia and Chronic Myeloid Leukemia were the most remarkable malignant hematological disorder diagnosed on bone marrow aspiration in Quetta.

Key words: Bone Marrow Aspiration, Benign, Hematological Disorders, Malignant.

Article Citation: Dogar AS, Ejaz B, Farooq HA, Mahmood T. Spectrum of benign and malignant hematological diseases diagnosed in Quetta on bone marrow aspiration. Professional Med J 2020; 27(3):641-645.

DOI: $10.29309 / \mathrm{TPMJ} / 2020.27 .3 .4210$

\section{INTRODUCTION}

Bone marrow aspiration is a valuable test these days. It has become an essential tool in diagnosing and finalizing the spectrum of hematological disorders both benign and malignant. Bone marrow aspiration is a safe invasive procedure with the risk of adverse events associated with it is found to be $0.08 \% .^{1}$ It is a commonly performed test as it provides detailed information regarding the diagnosis of cytopenias, metastatic deposit, leukemias, hemoparasites and storage diseases with rarely reported incidence of bleeding and infection. ${ }^{1,2,3,4}$ Bone marrow aspiration displays reliable information regarding bone marrows architecture, cellularity and about different stages of blood cells maturation. ${ }^{5}$

Hematological disorders are commonly found among different age groups. They usually range from anemias to advanced hematological malignancies. ${ }^{6}$ Moreover the pattern of hematological disorders is quite different in developed countries than from developing countries. ${ }^{2,7}$

In Pakistan among the benign hematological causes of nutritional deficiency anemia most commonly found is megaloblastic anemia having the highest frequency, followed by mixed deficiency anemia and the least common is Iron deficiency anemia. ${ }^{2,8}$ Nevertheless aplastic /hypoplastic anemia and idiopathic thrombocytopenic purpura were quite common in our population. The malignant spectrum showed acute lymphoblastic leukemia having highest prevalence in less than 20 years age group 
followed by chronic myeloid leukemia mostly diagnosed on routine complete blood counts with marked hyper leukocytosis. Geographical distribution and demographic features can lead to these patterns that are observed as our as it was conducted in Quetta.

\section{OBJECTIVES}

The objective of this study was to determine the sex and age distribution, and the spectrum of hematological disorders both benign and malignant diagnosed on bone marrow aspiration in Quetta.

\section{MATERIAL AND METHODS}

This cross-sectional study was carried out in the Department of Pathology, Bolan Medical Hospital and Sandeman Provincial Teaching Hospital Quetta, over a period of four years from January 2015 to January 2019. Total 478 patients having hematological disorder diagnosed on bone marrow aspiration were included in our study. Along with history, clinical presentation, examination and relevant laboratory investigations were noted on a standard proforma. Complete data was analyzed and results were compiled on the basis of frequencies and percentages of these hematological disorders in patients of Quetta. Complete blood counts were done on automated hematology analyzer, SysmexK $x^{20}$. The bone marrow aspiration was performed following standard protocol and the procedure was done under aseptic technique. The preferred site was posterior superior iliac spine in above two years age group and from tibia in children less than two years of age. The bone marrow aspirate slides were stained with Giemsa and Leishman stain followed by preparation of smears. Bone marrow aspiration smears were examined for the presence of cellularity, maturation and differentiation of myelopoiesis, erythropoiesis, megakaryopoiesis, hemoparasite, extra medullary cells and immature cell.

The demographic variables were age and gender of the patients, while the research variables were types of hematological disorder, benign and malignant. All the variables were presented in percentages and frequencies. The inclusion criteria included all patients with bone marrow aspiration and few had bone marrow trephine showing either benign or malignant hematological disorder.

\section{RESULTS}

All this categorical data was analyzed manually by frequency and percentage. Out of 478 cases $263(55.1 \%)$ were males and $215(44.9 \%)$ were females (Table-I) the male to female ratio of 1.2:1.

\begin{tabular}{|l|c|c|}
\hline \multicolumn{1}{|c|}{ Gender } & No of Patients & Percentage (\%) \\
\hline Male & 266 & 55.1 \\
\hline Female & 215 & 44.9 \\
\hline Total & 478 & 100 \\
\hline & Table-l. Gender Distribution. \\
\end{tabular}

Maximum number of patients $173(36.1 \%)$ were in age group of 1-10 years, followed by 117 (24.4\%) were between 11 to 20 years age group, while lowest number $6(1.2 \%)$ were less than 01 years age group (Table-II).

\begin{tabular}{|c|l|c|c|}
\hline $\begin{array}{c}\text { Sr. } \\
\text { No }\end{array}$ & Age (years) & $\begin{array}{c}\text { No of } \\
\text { Patients }\end{array}$ & $\begin{array}{c}\text { Percentage } \\
\text { (\%) }\end{array}$ \\
\hline 1 & $1>$ & 6 & 1.25 \\
\hline 2 & $1-10$ & 173 & 36.19 \\
\hline 3 & $11-20$ & 117 & 24.47 \\
\hline 4 & $21-30$ & 49 & 10.25 \\
\hline 5 & $31-40$ & 38 & 7.94 \\
\hline 6 & $41-50$ & 35 & 7.32 \\
\hline 7 & $51-60$ & 33 & 6.90 \\
\hline 8 & $61<$ & 27 & 5.64 \\
\hline & Total & 478 & 100 \\
\hline
\end{tabular}

Table-II. Age Distribution in Hematological Disorders.

The total number of bone marrow aspirations done was 525 to find out the spectrum of hematological disorders out of which 478 cases were positive for hematological disorder then they were further categorized into benign and malignant diseases.

Out of total 478 patients $241(50.4 \%$ ) hematological patients showed benign disorders (Table-III) and $237(49.6 \%)$ were diagnosed as having a malignant hematological disorder (Table-IV). 
Among the benign hematological disorders the commonest disorders was megaloblastic anemia $68(14.2 \%)$ followed by hypoplastic / aplastic anemia in 56(11.7\%), idiopathic thrombocytopenic purpura 44(9.2\%), mixed/ double deficiency anemia $38(7.9 \%)$, erythroid hyperplasia $23(4.8 \%)$.

Less common benign disorders were visceral leishmaniasis diagnosed in $5(1.0 \%)$, storage disease $4(0.8 \%)$, whereas hemophagocytic syndrome, osteopetrosis \& Iron deficiency anemia were all found to be $1(0.2 \%)$ of the patients.

\begin{tabular}{|c|l|c|c|}
\hline $\begin{array}{c}\text { Sr. } \\
\text { No. }\end{array}$ & \multicolumn{1}{|c|}{ Benign } & (n) & $\begin{array}{c}\text { (\%) } \\
\text { age }\end{array}$ \\
\hline 1 & Megaloblastic Anemia & 68 & 14.2 \\
\hline 2 & Aplastic Anemia & 56 & 11.7 \\
\hline 3 & $\begin{array}{l}\text { Idiopathic Thrombocytopenic } \\
\text { purpura }\end{array}$ & 44 & 9.2 \\
\hline 4 & Mixed Defiency Anemia & 38 & 7.9 \\
\hline 5 & Erythroid Hyperplasia & 23 & 4.8 \\
\hline 6 & Visceral Leishminasis & 5 & 1.0 \\
\hline 7 & Storage Disease & 4 & 0.8 \\
\hline 8 & Hemophagocytic Syndrome & 1 & 0.2 \\
\hline 9 & Osteopetrosis & 1 & 0.2 \\
\hline 10 & Iron Defiency Anemia & 1 & 0.2 \\
\hline \multicolumn{2}{|c|}{ Total disorders. } & 241 & 50.2 \\
\hline & Table-III. Spectrum of Benign Hematological \\
\hline & \multicolumn{2}{|c|}{} \\
\hline
\end{tabular}

Among the malignant hematological disorder group, acute lymphoblastic leukemia was diagnosed in maximum number of patients $91(19 \%)$ in descending order followed by chronic myeloid leukemia 40(8.3), acute myelogenous leukemia 28(5.8\%), chronic lymphocytic leukemia 19(3.9\%), multiple myloma 14(2.9), lymphoproliferative disorder 13(2.7).

Secondary metastatic deposits were found in $12(2.5 \%)$ cases non - hodgkin lymphoma 6(1.2\%) plasma cell dyscrasia and myelodysplastic syndrome were all found in $4(0.8 \%)$, hairy cell leukemia 3(0.6\%) hodgkin lymphoma 2(0.4\%) and polycythemia rubura vera was seen in $01(0.2 \%)$.

\begin{tabular}{|c|c|c|c|}
\hline $\begin{array}{l}\text { Sr. } \\
\text { No. }\end{array}$ & Malignant & $\mathbf{n}$ & $\begin{array}{l}\text { (\%) } \\
\text { age }\end{array}$ \\
\hline 1 & Acute Lymphobalastic Leukemia & 91 & 19.03 \\
\hline 2 & Chronic Myeloid Leukemia & 40 & 8.36 \\
\hline 3 & Acute Myelogenous Leukemia & 28 & 5.85 \\
\hline 4 & Chronic Lymphocytic Leukemia & 19 & 3.97 \\
\hline 5 & Multiple Myloma & 14 & 2.92 \\
\hline 6 & Lymphoproliferative Disorder & 13 & 2.71 \\
\hline 7 & Secondaries & 12 & 2.51 \\
\hline 8 & Non Hodgkin Lymphoma & 6 & 1.25 \\
\hline 9 & Plasma Cell Dyscrasia & 4 & 0.83 \\
\hline 10 & Myelodysplastic Syndrome & 4 & 0.83 \\
\hline 11 & Hairy Cell Leukemia & 3 & 0.62 \\
\hline 12 & Hodgkin Lymphoma & 2 & 0.41 \\
\hline 13 & Polycythemia Rubura Vera & 1 & 0.20 \\
\hline 14 & Total & 237 & $49.5 \%$ \\
\hline
\end{tabular}

\section{DISCUSSION}

Bone marrow aspiration remains an essential tool in the initial provisional diagnosis and management of a large variety of both benign and malignant hematological disorders. All these categorical data was analyzed manually by frequency and percentage.

Out of 478 cases 263(55\%) were males and $215(45 \%)$ were females the male to female ratio of $1.2: 1$. This study was similar to the studies conducted by Mansoor et $\mathrm{al}^{9}$ and Rajendra et al. ${ }^{21}$

Maximum number of patients $173(36.1 \%)$ were in age group of $1-10$ years, followed by $117(24.4 \%)$ were between 11 to 20 years age group, while lowest number $6(1.2 \%)$ were less than 01 years age group.

Benign hematological disorder spectrum in our study comprised of $241(50.2 \%)$ cases and the most common deficiency anemia reported in our population was Megaloblastic anemia 68(14.2\%) which is in accordance to multiple studies done in Pakistan and other countries with a fluctuating frequency between $24 \%{ }^{4}$ to $68 \%$ is observed. ${ }^{10,11}$ Moreover the commonest finding on complete blood counts was pancytopenia in our as well 
as in multiple other national \& international studies. ${ }^{12,13,14,15}$ Diagnosis of megaloblastic anemia depends on finding the megaloblastic maturation within the bone marrow. ${ }^{16}$ Microcytic anemia (iron deficiency) was the least common of micronutrient anemias in $1(0.2 \%)$ cases, much lower percentage when compared with world population $60-80$ percent. ${ }^{17}$

Hypoplastic/Aplastic anemia was the second common benign disorder in our patients $56(11.7 \%)$. In our majority of cases the etiology was found to be positive drug intake history and pesticides. It was in accordance to the studies conducted in Thailand ${ }^{13}$ and China. ${ }^{14}$ Idiopathic thrombocytopenic purpura 44(9.2\%) comprised of the third major cause of benign hematological disorder most common presentation was petechiae, cutaneous / mucosal hemorrhagic manifestations, which was similar to the study conducted by Mansoor et al 2017. ${ }^{9}$ Few studies reported the frequency of ITP between 32$48 \% .{ }^{11,18}$ In micronutrient anemia's Iron deficiency anemia was least common $1(0.2 \%)$, markedly reduced percentage when compared with 6080 percent prevalent in the world population. ${ }^{12}$ Mixed deficiency anemia was found in 38(7.9\%) the cause indicated was as mostly patients were already on iron supplements. $28(4.8 \%)$ showed erythroid hyperplasia, 5 patients on examination had massive splenomegaly were diagnosed as having visceral leshminasis. 4 cases were positive for storage disease (Gaucher and Niemann pick disease) were diagnosed. The least common disease of the benign hematological origin was hemophagocytic syndrome, osteopetrosis and iron deficiency anemia.

Malignant hematological disorders in our study were $237(49 \%)$ patients. Out of these $119(24.8 \%)$ cases belonged to acute leukemia's with 91(19\%) were acute lymphoblastic leukemia our study was in accordance to three other studies were acute lymphoblastic leukemia incidence was reported as $13.6 \%{ }^{19}, 16.1 \%{ }^{18}$ and $17.9 \% .{ }^{20}$ The second common malignant disorder observed in the population of Quetta was chronic myeloid leukemia in $40(8 \%)$ cases who presented with marked hyper leukocytosis and splenomegaly.
Whereas in a study conducted in Abbottabad only $2.4 \%{ }^{15}$ showed CML. Moreover acute myelogenous leukemia was seen in $28(5.8 \%)$ which resembled the study done by Mansoor et al $100(5.5 \%) .{ }^{9}$ Chronic lymphocytic leukemia $19(3.9 \%)$ was more common in males between 35-70 years age group and mostly had cervical lymphadenopathy along with hepatosplenomegaly. Multiple myloma was seen in 14 patients, lymphoproliferative disorders comprised of a small group of 12 patients. 10 patients had secondaries / metastasis. ${ }^{1,21}$ Nonhodgkin lymphoma cases were 5, juvenile chronic lymphocytic leukemia, plasma cell dyscrasia, myelodysplastic syndrome were all reported in 4 patients. Whereas 3 cases were of hairy cell leukemia, 2 malignant hematological cases were of Hodgkin lymphoma with prominent Reedsternberg cells and the least common was polycythemia rubura vera $1(0.2 \%)$ in our study. ${ }^{3-19}$

\section{CONCLUSION}

It was concluded that the prevalence of hematological diseases depends upon age group like acute lymphoblatic leukemia was found mostly in the age group between $1-10$ years. Male were more prone to hematological diseases. Among the benign group nutritional anemias were common like megaloblastic anemias. Acute lymphoblastic leukemia was most common in malignant hematological disorders found in Quetta on bone marrow aspiration.

\section{Copyright 30 Dec, 2019.}

\section{REFERENCES}

1. Hoffman R, Benz EJ, Shattil SJ. Hematology: Basic Principles and practice. 5th ed. Philadelphia: Churchill Livingstone; 2008.

2. Rahim F, Ahmad I, Islam S, Hussain M, Khattak TA, Bano Q. Spectrum of hematological disorders in children observed in $\mathbf{4 2 4}$ consecutive bone marrow aspirations/biopsies. Pak J Med Sci 2005; 21:433-6.

3. Westerman MP. Bone marrow needle biopsy: An evaluation and critique. Semin Hematol 1981; 18:293300 .

4. Bain BJ. Bone marrow aspiration. J Clin Pathol 2001; 54:657-63 
5. Bain BJ. Bone marrow biopsy morbidity: Review of 2003. J Clin Pathol 2005; 58:406-8.

6. Pudasaini S, Prasad K, Rauniyar S, Shrestha R, Gautam $\mathrm{K}$, Pathak R, et al. Interpretation of bone marrow aspiration in hematological disorder. $J$ Path Nepal 2012; 2:309-12.

7. Young NS, Abkowitz JL, Luzzatto L. New insights into the pathophysiology of acquired cytopenias. Hematology Am Soc Hematol Educ Program 2000:1838.

8. Anjum MU, Shah $\mathrm{SH}$, Khaliq MA. Spectrum of hematological disorders on bone marrow aspirate examination. Gomal J Med Sci 2014; 12: 193-6.

9. Mansoor SN, Ali M, Mueez F, Nadeem SM, Nadeem W, Nadeem SM. Hematological diagnosis in children: Results of a $\mathbf{1 0}$ year long cohort based upon bone marrow examination. P J M H S 2017; 11: 664-7

10. Iqbal W, Hassan K, Ikram N, Nur S. Etiological break up of $\mathbf{2 0 8}$ cases of pancytopenia. J Rawal Med Coll 2001; 5:7-10.

11. Mussarat $N$, Raziq $F$. The incidence of underlying pathology in pancytopenia. An experience of $\mathbf{8 9}$ cases. J Postgr Med Inst 2004; 18(1).76-9.

12. Ng SC, Kuperan P, Chan KS, Bosco J, Chan GL. Megaloblastic anemia. A review from University Hospital, Kuala Lumpur. Ann AcadMed Sing 1988; 17:261.

13. Qazi RA, Masood A. Diagnostic evaluation of pancytopenia. J Rawal Med Coll 2002: 6(1):30-3.
14. Ikram N, Hassan K, Bukhari K. Spectrum of hematological lesions amongst children as observed in 963 consecutive BM biopsies. J Pak Inst of Med Sci 2002; 13:686-90.

15. Iqbal W, Akhtar H, BaqaiT, Rehman M, Muzzafar M. Morphological features in $\mathbf{4 0}$ cases of megaloblastic anemia. J Rawal Med Coll 2003; 19:39-42.

16. Khan MN, Ayyub M, Naqi N, Hussain T, Shujaat $H$, anwar M, Pancytopenia: Clinicopathological study of 30 cases at Military Hospital, Rawalpindi. Pak J Path $2001 ; 12: 37-41$.

17. Mohammad AJ. Thrombocytopenia in children. $J$ Postgr Med Inst 2004; 18: 353-8. Hoffbrand AV, Green R. Blackwell publishing Ltd. 350 main street, Malden, Massachutes 02418-5021,USA.2005;60-6

18. Issaragrisil S, Chansung K, Kanfman DW, et al. Aplastic anemia in rural Thailand: Its association with grain farming and pesticide exposure. Am J Public Health 1997; 87:1551-4.

19. Ekwere TA, Ino-Ekanem MB, Motilewa OO. Global journal of hematology and blood transfusion, 2015; 2:4-8.

20. Rajendra KN, Reeni M, Suhas K, et al. Spectrum of diseases diagnosed by bone marrow examination in central India. Journal of Evolution of Medical and Dental Sciences 2014; 3: 326-337

21. Riley RS, Hogan TF, Pavot DR, et al. A pathologist's perspective on bone marrow aspiration and biopsy: I. Performing a bone marrow examination. J Clin Lab Anal. 2004; 18:70-90.

\begin{tabular}{|c|c|c|c|}
\hline \multicolumn{4}{|c|}{ AUTHORSHIP AND CONTRIBUTION DECLARATION } \\
\hline Sr. \# & Author(s) Full Name & Contribution to the paper & Author(s) Signature \\
\hline 1 & Ayesha Samad Dogar & Collection of data. & As $-\infty \pi_{3} 2$ \\
\hline 2 & Beenish Ejaz & COmplilation of data. & Beomin \\
\hline 3 & Hafiz Ather Farooq & Finding related articles. & SAthenoor \\
\hline 4 & Tariq Mahmood & Compilation of data. & To Monniod \\
\hline
\end{tabular}

